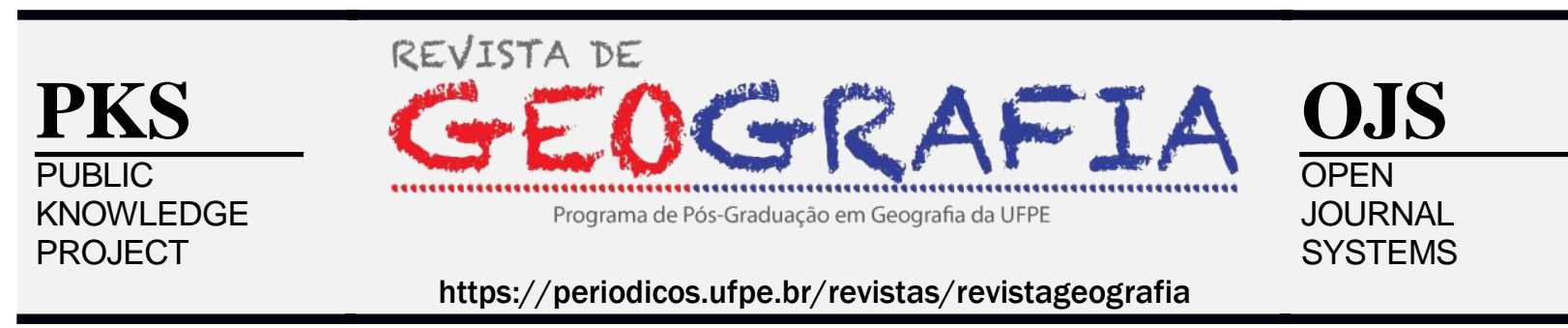

\title{
O PAPEL E IMPORTÂNCIA DA CIÊNCIA GEOGRÁFICA ENQUANTO FERRAMENTA DE EMANCIPAÇÃO SOCIAL: O CONTEXTO ESCOLAR
}

\author{
Émerson Dias De Oliveira ${ }^{1}$, Tamila Eduarda Souza ${ }^{2}$, Milena Ferreira Almeida ${ }^{3}$, \\ Halana Rafaela Rocha Tavares ${ }^{4}$
}

\footnotetext{
${ }^{1}$ Docente do Colegiado de Pedagogia da UNIVALE: e-mail: cooperativismopopular@hotmail.com.

${ }^{2}$ Licenciada em Pedagogia pela UNIVALE: e-mail: milenaferreiradealmeida@gmail.com.

${ }^{3}$ Licenciadaem Pedagogia pela UNIVALE: e-mail: milenaferreiradealmeida@gmail.com.

${ }^{4}$ Licenciadaem Pedagogia pela UNIVALE: e-mail: cooperativismopopular@hotmail.com.
}

Artigo recebido em 19/05/2019 e aceito em 26/11/2019

\begin{abstract}
RESUMO
A disciplina de Geografia tem sua construção social já datada desde o século XIX na Europa, a qual esteve a serviço da unificação nacionalista daqueles Estados-Nação. No Brasil a Geografia também fio utilizada por seus diversos governantes, desde o período imperial, para instituir uma unidade nacional. Portanto, esta ciência historicamente esteve ligada aos propósitos de uma elite dominante que buscava a perpetuação do seu poder tanto em nível nacional quanto internacional. Assim, ao longo deste estudo se reflete o surgimento e consolidação da Geografia enquanto disciplina singularizada, um esforço que também se deu no meio escolar. O intento ao final do estudo busca trazer à tona a importância que a Geografia escolar apresenta na atualidade enquanto uma ferramenta de interpretação do espaço, situando os sujeitos sociais acerca do seu papel e lugar no mundo. A abordagem aqui levantada questiona também necessidade de entender a Geografia enquanto uma construção social única e enviesada em uma perspectiva totalitária, isto é, um entendimento do espaço geográfico enquanto uma sobreposição de inúmeras possibilidades sociais, compreensão esta que supera as visões fragmentadas e até tendenciosas na qual a Geografia esteve submetida até meados do século XX.
\end{abstract}

Palavras-chave: Geografia Científica; Ensino; Ciência; Ensino Geográfico; Sociedade.

\section{THE ROLE AND IMPORTANCE OF GEOGRAPHICAL SCIENCE AS A TOOL FOR SOCIAL EMANCIPATION: THE SCHOOL CONTEXT}

\begin{abstract}
The discipline of Geography has its social construction already dated since the nineteenth century in Europe, which was at the service of the nationalist unification of those nation-states. In Brazil, Geography has also been used by its various rulers since the imperial period to establish a national unity. Therefore, this science has historically been linked to the purposes of a ruling elite that sought to perpetuate its power both nationally and internationally. Thus, throughout this study reflects the emergence and consolidation of Geography as a unique discipline, an effort that also occurred in the school environment. The attempt at the end of the study seeks to bring to light the importance that the present School Geography presents as a tool of interpretation of the space, situating the social subjects about its role and place in the world. The approach raised here also questions the need to understand Geography as a unique and biased social construction in a totalitarian perspective, that is, an understanding of geographical space as an overlapping of innumerable social possibilities, an understanding that surpasses fragmented and even tendentious visions in which Geography was submitted until the middle of the 20th century.
\end{abstract}

Keywords: Scientific Geography; Teaching; Science; Geographical Teaching; Society. 


\section{INTRODUÇÃO}

A abordagem da geografia enquanto disciplina escolar tem se apresentado de forma desafiadora para uma grande maioria de seus respectivos professores, pois ainda se percebe a prática de um modelo pedagógico tradicional, descritivo e memorístico desta ciência nas escolas do país. É esta a provocação destacada no presente estudo, refletir a importância e necessidade de se construir um ensino geográfico que esteja efetivamente alinhado com o cotidiano discente, isto é, possibilitar aos educandos um posicionamento crítico da realidade, pois estes carecem de estarem inseridos de forma propositiva diante dos questionamentos encarados no seio familiar, no meio comunitário, no mundo do trabalho, na aprendizagem escolar e nas demais instituições das quais são produto e construtores.

Aqui se busca validar uma Geografia que seja elaborada para e pelo educando, situando a realidade do mesmo. É uma explicação do espaço geográfico na perspectiva deste próprio limite, buscando a desenvoltura do senso crítico no meio escolar a fim de que os alunos passem a se posicionar de forma reativa e propositiva perante a realidade social que lhe é apresentada, isto é, institui uma educação concreta e carregada de intentos emancipatórios. "Dessa forma, tem-se uma tomada de consciência sobre as responsabilidades, os direitos e deveres sociais, com o intuito de efetivamente tornar o aluno agente de mudanças desejáveis para a sociedade" (LANDIM NETO; BARBOSA, 2010, p. 162). Tal possibilidade só é realizável em virtude da Geografia escolar ser ao mesmo tempo, tanto uma ferramenta quanto um recurso metodológico para se fazer a leitura do espaço e do tempo vivenciados pelos sujeitos sociais.

Nesta conjuntura, surge o papel do professor (a) da disciplina de geografia, o qual deve buscar uma verdadeira aproximação entre as várias geografias estudadas e o vivido do aluno. Esta necessidade decorre do fato de que "a compreensão do espaço geográfico pressupõe o desenvolvimento do olhar espacial, especialidade da Geografia, o qual proporciona as condições para a efetiva aprendizagem geográfica, valorizando o movimento, a contextualização e o cotidiano" (TONINI, 2011, p.24).

A necessidade de se fazer esta discussão decorre do fato de ainda estar presente entre os alunos uma significativa dificuldade em se compreender os vínculos e apreensões conceituais da ciência geográfica, sendo que nem sempre os discursos proferidos em sala de aula apresentam um alinhamento com a prática social dos próprios e até mesmo com as abordagens incorridas em provas, vestibulares e no ENEM. Não é a memorização fragmentada das 
geografias que garantirá a sua aprendizagem, mas uma adequada contextualização social tempo-espacialmente, além da interação didático-pedagógica com os demais conteúdos disciplinares. Em relação à Geografia escolar pautada apenas na memorização, Callai (2001, p. 139) a descreve como uma finalidade pedagógica porosa e deslocada de sentido, traduzindo assim "[...] em aulas sobre relevo, vegetação, clima, população, êxodo rural e migrações, estrutura urbana e vida nas cidades, industrialização e agricultura, estudados como conceitos abstratos, neutros, sem ligação com a realidade concreta da vida dos alunos".

Esta preocupação se insere junto ao movimento de renovação da Geografia, uma evolução que permeia tanto o meio acadêmico como o escolar, sendo que esta preocupação ganhou centralidade após os anos 1960, dada a influência a pulverização das ideias marxistas, oportunidade em que foi forjada uma crítica à Geografia Tradicional. É deste cenário que emerge entre os anos 1970/80 a chamada Geografia Crítica, um entendimento renovado e que se posiciona de forma contrária a aparente neutralidade e objetividade da perspectiva quantitativa das geografias propostas até então. "No caso do Brasil, a Geografia Crítica nasce no final da década de 70, cujo marco foi o $3^{\circ}$ Encontro Nacional dos Geógrafos, realizado em julho de 1978 em Fortaleza-CE, sob os auspícios dos Geógrafos Brasileiros” (CORRÊA, 1991, p. 20).

Assim sendo, através desta problemática busca-se entender como as práticas pedagógicas podem contribuir na (re) construção do ensino geográfico na Educação Básica. Para tanto, a elaboração do presente estudo utilizou enquanto método científico a pesquisa bibliográfica, uma vez que tal procedimento permitiu uma melhor conexão ao tema proposto, sendo que a sua realização se deu através de um esforço significativo em publicações referentes ao tema em questão. As características desse método permitem a abrangência e o fácil entendimento de fontes de conhecimento, através de artigos, livros, jornais e etc.

Para Marconi e Lakatos (2003), o aporte bibliográfico “oferece meios para definir e resolver não somente problemas já conhecidos, como também explorar novas áreas onde os problemas não se cristalizaram suficientemente" (p. 183). Corroborando desta ideia, Lakatos (1991) destaca que esse tipo de pesquisa "não é apenas uma repetição do que já foi falado ou escrito sobre determinado assunto, mas sim, uma forma de examinar o tema sobre um novo enfoque, podendo chegar a conclusões inovadoras" (p. 66). As discussões aqui levantadas é também fruto dos estudos elaborados na disciplina de Metodologia da Pesquisa em Geografia e História do curso de Licenciatura em Pedagogia junto as Faculdades Integradas do Vale do Ivaí, reflexões estas que foram elaboradas ao longo do primeiro semestre de 2019. 
Com isso, a proposta colocada no presente estudo esteve voltada em dialogar o viés interdisciplinar na geografia escolar, uma sistematização prático-teórica que "precisa ser estimulada na escola, para auxiliar no entendimento do mundo e da realidade contraditória vivida pela sociedade" (PONTUSCHKA, 2009, p. 146). Portanto, a cristalização de posturas metodológicas é essencial para que essa geografia, de fato, esteja presente no meio escolar, dando ênfase ao conhecimento empírico do aluno, buscando sistematizá-lo em científico, um esforço que tem como propósito construir vinculações entre o sujeito da aprendizagem e o objeto de estudo. Dado este desafio, Cavalcanti (2006) indica algumas questões a serem consideradas quando da prática docente na Geografia escolar:

\footnotetext{
O que é a Geografia escolar na atualidade? Como ela se realiza? Como o professor a constrói? Quais os desafios da prática do ensino da Geografia? Quem são os alunos da Geografia? Como são esses alunos? Como praticam a Geografia do dia-a-dia? Como aprendem Geografia na escola? Que significados têm para os alunos aprender Geografia? Que dificuldades eles têm para aprender os conteúdos trabalhados nessa disciplina? (CAVALCANTI, 2006, p. 66).
}

Tendo em vista essa provocações, Melo (2018) pontua que o ensino de Geografia instituído de forma padronizada e/ou linear acaba comprometendo a formação dos sujeitos enquanto profissionais capazes de atuarem em sincronia com a tríade ensino-pesquisa-extensão. Com isso, é cada vez mais necessário pensar e construir propostas de ensino com um caráter mais dinâmico, o qual não seja visto tão somente na perspectiva da velocidade, mas com uma organização de interatividade, as chamadas metodologias ativas. A necessidade de todo esse cuidado metodológico, didático e teórico deve-se ao fato de que o próprio sistema educacional formal se dá posteriormente ao processo de formação social.

Nesse sentido, é de extrema importância refletir a Geografia escolar enquanto uma ferramenta que leve em consideração os sentidos do aluno. O desafio se percebe na dificuldade de construir uma Geografia do ensino que supere os entendimentos disciplinares voltados na memorização de fenômenos geográficos. Assim, aqui está discutida a realização de uma Geografia com fundamentação fenomenológica e ensinada a partir de teorias construtivistas, um esforço que busca instituir nos estudantes a capacidade de compreender o espaço a partir de referenciais concretos. Além disso, está discutido também de forma abreviada o surgimento e consolidação da Geografia enquanto disciplina científica autônoma.

\section{A GEOGRAFIA ENQUANTO UMA CONSTRUÇÃO CIENTÍFICO-ACADÊMICA}

\begin{tabular}{llr}
\hline Oliveira et al, 2019. & ISSN 0104-5490
\end{tabular}


A interação das sociedades humanas com a natureza é uma realização necessária para a sobrevivência e perpetuação destes sujeitos, sendo que neste processo tem-se uma acentua transformação do espaço em conformidade as demandas sociais. Esta organização faz parte do cotidiano humano há centenas de anos, retrocedendo em tempos pré-históricos que pouco ou quase nada se sabe de forma objetiva, mas nem por isso o homem já não deixava de grafar o espaço, portanto, a Geografia é um produto (mesmo sem saber ou querer) presente desde as ocupações humanas mais remotas do planeta. É por isso que a Geografia traz em si um caráter interdisciplinar, pois abrange um arcabouço composto por distintos saberes e conhecimentos, ou seja, ela é concebida como "[...] a ciência que estuda, analisa e tenta explicar (conhecer) o espaço produzido pelo homem” (CALLAI, 1998, p. 57).

A importância da Geografia enquanto disciplina científica é uma verdade tão explícita que sem as contribuições desta ciência, o homem não teria conseguido atingir ao atual estágio evolutivo. Bem antes de a Geografia ter sido sistematizada enquanto ciência independe, situação esta que aconteceu tardiamente já no século XIX, os conhecimentos geográficos já eram amplamente utilizada em benefício dos grupos populacionais. Acerca das primeiras organizações societárias Andrade (1987) destaca que “[...] mesmo sem possuírem a escrita, transmitindo os conhecimentos através da versão oral e dos desenhos em rochas e em cavernas, passadas de geração a geração, tinham uma concepção de vida e uma cultura, ambas impregnadas de ideias geográficas" (p. 20), portanto, não deixavam de também estarem produzindo Geografia. É por isso que a história da Geografia tem início com a história do homem na Terra.

Com isso, as migrações humanas, conhecer os mecanismos das estações, a invenção da agricultura, a domesticação de animais, a caça e a coleta, o conflito entre os grupos humanos, e demais construções sociais podem ser considerados parte dos primeiros conhecimentos geográficos, um cenário em que a palavra de ordem era a sobrevivência. É na correlação destes e outros saberes que se vai forjando a condição para a supremacia da raça humana na terra, um processo que acabou diferenciando os próprios grupos humanos, surgindo assim o domínio de uns em detrimentos de outros. Portanto, a Geografia vai além das assimilações físicas da superfície terrestre, constitui também uma dimensão humana, ganhado centralidade a questão da política, economia, cartografia, governos, servidão, dentre outras perspectivas geográficas (ANDRADE, 1987). 
A geografia produzida até então permitiu a expansão do homem para as mais longínquas extremidades terrestres, criando uma diversidade povos com suas culturas singulares. Já por volta do século VII ao século IV a.C a humanidade havia constituído uma sociedade com uma organização tão bem elaborada como os povos contemporâneos com a chamada Grécia Antiga, dada ao conjunto de cidades que compartilhavam a língua, costumes e algumas leis. A filosofia grega que era figurada em renomados sábios buscava explicar o mundo em termos físicos, buscando superar a explanação dos fenômenos naturais ocasionados pelo mito, isto em territórios das atuais: Europa, Ásia e África. Para Lencioni (1999), os “[...] gregos pertencentes à escola jônica de filosofia podem ser considerados como os primeiros geógrafos, num sentido figurativo, por terem sido pioneiros na construção de um conhecimento metódico" (p. 36).

O próprio nome geografia (descrever a Terra) foi uma criação grega, povos que originalmente se preocuparam com a sistematização desse conhecimento. Aqui a Geografia avança da fase da "coleta", isto é, momento em que obtêm dados e informações, para o estágio da "sistematização", condicionantes para a elaboração metodológica do saber. Sistematizar já é um comportamento da ciência moderna, e esse progresso na forma de se produzir o conhecimento geográfico foi essencial para que os primeiros ensaios ou teorias geográficas acontecessem. Entre os vários estudiosos deste período, Eratóstenes de Cirene (275-194 a.C.) é tido como o pai da Geografia na Antiguidade, em função dos importantes estudos sobre as medições da Terra que realizou. Conseguiu provar a esfericidade da Terra utilizando-se de métodos astronômicos e geométricos, sendo que chegou ao cálculo de 42000 quilômetros, valor bem próximo da medida exata. Entre outras várias contribuições geográficas, Eratóstenes construiu um mapa-múndi que é tido como o primeiro registro cartográfico que se utiliza de coordenadas geográficas (RIBAS, 2015).

No entanto, esta Geografia Clássica teve a sua continuidade barrada com a chegada da Idade Média (476 d.C. - 1453), período que ficou marcado pela hegemonia da Igreja Católica enquanto a maior detentora do poder político e econômico, a qual proibia o pensamento e o questionamento aos sujeitos.

A adoção dos conhecimentos geográficos bíblicos tornou-se evidente na cartografia. Utilizam-se mapas circulares romanos, nos quais introduziram caracteres teológicos, e não geográficos. Assim, Jerusalém, a Cidade Santa, ocupava o centro do mapa; o Paraíso, localizado a leste, ocupava a parte superior do mapa; o Mediterrâneo tinha uma posição mediana. Foi esquecido que a Terra era esférica e reapareceu o conceito de Terra plana: um disco circundado de água. (FERREIRA; SIMÕES, 1990, p. 4546). 
Este cenário será superado com a ascensão da razão sobre o dogmatismo da religiosidade medieval, é a inauguração de um período caracterizado pelo Renascimento Cultural, a Reforma Protestante e a Contra Reforma Católica, as Grandes Navegações, o Colonialismo e o Mercantilismo, o advento do Capitalismo Comercial e o início dos Regimes Absolutistas, o descobrimento de novas terras. Enfim, um novo mundo é descortinado e a ciência surge novamente enquanto elemento fundamental para a constituição desta nova realidade social. Entre os vários pensadores deste período se fazia presente um geógrafo que inaugurou o papel de destaque da Geografia na modernidade, o holandês Bernhardus Varenius (1622 - 1650). Em sua obra “Geografia Geral”, publicada originalmente em 1650 já se faziam presente reflexões alinhadas com a Geografia Moderna, tendo alusões a autores clássicos como Copérnico e Galilei. Seus estudos clamam “[...] por uma aplicabilidade, pela produção de um saber útil ao comércio, ao Estado. Exalta o recuo das áreas de sonho, de mitos, em nome do conteúdo empírico que apareceria radiante caso o véu da ignorância fosse retirado das áreas do mundo, do globo terrestre" (BAUAB, 2005, p. 34).

A Geografia conhecida ainda como pré-científica e não sistematizada de forma isolada vai colaborar junta aos vários conhecimentos científicos para a construção do mundo moderno e contemporâneo, praticava-se até então uma Geografia de caráter eminentemente descritiva e com seus saberes dispersos, mas que nem por isso deixou de exercer importantes contribuições sociais. Portanto, tendo como base os postulados positivistas, a Geografia vai superar a máxima que lhe era apontada até então, ou seja, deixar de ser uma ciência empírica e que estava pautada na observação e adotar o método enquanto fundamento de verificação. Assim, as máximas e princípios "são os responsáveis pela unidade e continuidade da Geografia. [...] [...] Porém, tudo isso dissimulado sob a capa da tradição. A repetição constante das máximas e princípios vailhes dando um tom de verdade consuetudinária; fetichizam-se, adquirem ares de legitimidade" (MORAES, 2005, p. 08-09).

Fala-se assim em uma Geografia Tradicional, a qual buscava ser reconhecida no meio científico. Foi na Europa com os pesquisadores alemães Alexander Von Humboldt (1769-1859) e Karl Ritter (1779-1859), tidos inclusive como "pais da geografia moderna" que esta disciplina ganhou destaque frente à comunidade científica no decorrer do século XIX. A gênese científica da Geografia vai ser instituída então na Alemanha não por acaso, pois não havia ainda uma unificação em forma de Estado-nação, uma vez que o território resumia-se em dezenas de pequenos reinos. A Alemanha só foi unificar-se em 1870, considerada uma unificação tardia. “Temas como domínio e organização do espaço, apropriação do território, variação regional, 
entre outros, estarão na ordem do dia e na prática da sociedade alemã. É, sem dúvida, deles que se alimentará a sistematização geográfica” (MORAES, 2005, p. 46-47).

Humbolt se utilizou da observação e do método descritivo em seus estudos e viagens, além de refletir os aspectos relativos à organização social e política das sociedades que visitou. A Geografia é em seus estudos percebida enquanto uma ciência que entende a Terra enquanto totalidade, pois está composta por elementos que apresentam relações ordenadas entre si. Suas pesquisas resultaram na publicação mais bem elaborada da geografia tradicional-moderna, antes do surgimento da geografia da segunda metade do século XIX, a obra "Cosmos" que foi publicado em cinco volumes entre 1845 e 1862. A contribuição de Ritter está na compreensão das relações entre o meio natural e o desenvolvimento da sociedade. A individualização dos lugares é destacada e ganha centralidade o aspecto antropocêntrico e regional. Ele define o conceito de "sistema natural", isto é, uma área delimitada dotada de uma individualidade, cabendo a Geografia estudar estes arranjos individuais, e compará-los. Sua obra é explicitamente metodológica, esforço que ficou evidente em sua principal obra "Geografia Comparada” em 1809 (BAUAB, 2005).

Assim, inauguraram-se os pilares que condicionou a Geografia se posicionar atualmente enquanto uma ciência emancipada, uma contribuição que propiciou as várias perspectivas de se analisar a Geografia (política, agrária, econômica, demográfica, urbana, física, cartográfica, cultural, entre outras possibilidades diversas de estudo). Vale frisar também que a Geografia pode ser forjada ainda em sentidos particularizados, ou seja, antes de tudo é preciso se questionar de qual Geografia se está falando? Uma Geografia de cá ou de lá? O posicionamento do emissor refere-se a qual ótica geográfica? E qual a intencionalidade de uma dada geografia produzida? Estas são precauções de vital importância quando da inserção nos temários geográficos, um cuidado que serve para não tornar o envolvido em mero repetidor de ideologias contrárias ao lugar de onde se fala. E por fim, é possível discorrer também de duas outras possibilidades geográficas: a Geografia dos Estados Maiores e a Geografia dos Professores (LACOSTE, 1993). Este o desafio da ciência geográfica, carregar e explicar as várias faces do mundo, um esforço que faz uso de um método que dê conta dos inúmeros questionamentos que auxiliam a delinear o homem e sua relação com o espaço.

\section{A IMPORTÂNCIA DA GEOGRAFIA PARA O ENSINO ESCOLAR}


Considerando as colocações que de forma sucinta destaca o processo de surgimento e institucionalização da Geografia enquanto uma corrente científica autônoma, fica coerente discorrer uma Geografia de viés escolar. Novamente a necessidade de forjar ideologicamente e territorialmente o Estado-Nação alemão aparece aparecerá como a verdadeira causa de se estimular uma Geografia escolar. No início do século XIX, o império da antiga Prússia implanta uma formação básica para toda a sociedade, tornando obrigatório o ensino de uma língua nacional única e também a história e a Geografia na perspectiva do "amor à pátria" (VLACH, 1994). Assim, a Geografia começou a ser ensinada na escola porque era útil à classe dominante naquele momento histórico (LACOSTE, 1993).

\begin{abstract}
O nacionalismo patriótico, que varrerá a Europa a partir de Napoleão, dos fracassos de 1848 e da "via prussiana para o capitalismo" com Bismarck, encontra na idéia revolucionária da pátria e nas elaborações de Herder, no final do século XVIII, os elementos para produzir, por meio do Estado nacional, o sentimento nacional como consciência patriótica, o que permitirá, por seu turno, um duplo tratamento do "popular": como resíduo tradicional da nação (folclore) e como perigo contínuo para a pátria (as classes populares) (CHAỨ, 1983, p. 30).
\end{abstract}

Portanto, inicialmente a Geografia chega ao ambiente escolar com o intuito de servir a classe dominante, criando no ideário social a perspectiva nacionalista. A descrição e apresentação dos limites territoriais, o posicionamento do país no globo terrestre, as características culturais que singulariza o próprio Estado-Nação, entre outros esforços serviram para forjar a identidade patriótica (VLACH, 1994). A Geografia se constitui enquanto ferramenta para formar um futuro cidadão/soldado patriota. "Por privilegiar a descrição dos fenômenos físicos, cujos discursos foram atravessados pela causalidade natural, a Geografia foi posicionada como dispositivo para fabricação da identidade do povo alemão na escola" (TONINI, 2006, p. 31). Poucas décadas após, tem a criação de uma Geografia universitária com o propósito de preparar e formar os futuros professores do ensino escolar.

De acordo com Pereira (1999), é na Alemanha então que o ensino geográfico ensinado no ensino primário e secundário inaugurou seus primeiros passos, uma realização que se deu no decorrer da popularização da escolarização alemã ao longo do século XIX. "A Geografia é incluída nos currículos por razões geopolíticas enquanto não só marca a naturalidade do homem no espaço, mas também sustenta que o homem só é humano porque está incluído num espaço politizado, nacional” (PEREIRA, 1999, p.28). Dada as benesses que a Geografia proporcionava, este sentido passa também a ser partilhado por pelas demais nações européias, a exemplo da França após 1870, sendo que algumas literaturas discorrem que inclusive o saber 
geográfico sobre o território disputado por parte dos soldados alemães foi um dos motivos para a vitória alemã na guerra franco-prussiana.

Assim, tanto a construção de uma Geografia escolar nos países europeus como a sua posterior consolidação no Brasil, se dá de forma inteiramente contextualizada ao cenário histórico-geográfico dos grupos dominantes, os quais acabaram delineando os contornos de uma Geografia que atendesse aos seus interesses. A construção de uma "unidade nacional" brasileira também se utilizou da Geografia enquanto ferramenta metodológica para tal propósito, uma vez que o país havia recém declarado a sua independência (1822) e era necessário constituir um projeto único de nação no Império. Apesar do dificultoso desafio que este propósito representava em um território de dimensões continentais, o país já estudava propostas de um sistema nacional de ensino desde 1823, tarefa que não foi atingida em virtude das dificuldades de articulação interna e a resistência das oligarquias regionais e locais (VLACH, 2010).

Considerando a realidade brasileira, Rocha (2000, p. 129) aponta que "até o século XIX, os conhecimentos geográficos ensinados nos estabelecimentos educacionais existentes no Brasil não estavam organizados a ponto de constituírem uma disciplina escolar específica".Em 1832 a Geografia passou integrar o currículo no sistema escolar brasileiro, apesar de aparecer como uma disciplina secundária, já era autônoma, sendo que esta organização foi instituída pela reforma do Plano de estudos da Companhia de Jesus, denominado de Ratio Ataque Institutio Studiorum Societatis Jesu. Os conteúdos de Geografia já eram cobrados enquanto matéria escolar específica para as provas de ingresso nos Cursos Superiores de Direito desde 1831 no país (ROCHA, 2000). Nesse mesmo período, a Geografia alemã e francesa já se organizava cientificamente com base no positivismo das ciências naturais (método comparativo), resultando nos primeiros paradigmas da ciência geográfica.

A necessidade de um projeto de nação ao Império e sua vinculação com a Geografia ficou evidenciado pela criação do Instituto Histórico Geográfico do Brasil (IHGB) em 1838 no Rio de Janeiro (antiga Corte). Esta iniciativa tinha o propósito de destacar a figura da monarquia constitucional e forjar um ordenamento de unidade territorial, além disto, se buscava um acúmulo e sistematização de dados e informações sobre o território brasileiro. A questão da valorização geohistórica do país passou a ter uma ampla discussão nas escolas de primeiras letras, isto é, serviam como instrumentalização das elites para uma adequada condução da máquina pública de tal forma que se perpetuasse o statu quo. "Fica claro, portanto, (...) [que] os 'princípios republicanos anárquicos' são rejeitados e combatidos. A manutenção da 
monarquia é tomada como garantia e pressuposto para a integração do país" (GUIMARÃES, 2011, p. 69).

Neste mesmo período, no ano de 1837 é também criado o Imperial Colégio Pedro II, um esforço que buscava retratar no Brasil uma organização similar aos liceus franceses. Assim, “[...] desde 1838 a geografia era ministrada juntamente com história do Brasil, porém com o Decreto Monte Alegre de 1849, houve uma separação dessas disciplinas e a geografia passou a ser disciplina obrigatória em todas as séries do ensino secundário" (FELICIANO, 2015, p. 3927). O ensino desta Geografia caracterizava-se por ser descritiva, mnemônica e enciclopédica. Estruturava-se pelo ensino da Geografia Clássica - por meio dos cânones da Antiguidade - nos anos iniciais, sendo com o sexto ano passava-se para o estudo da descoberta do continente americano, suas regionalizações e os aspectos fisionômicos de suas paisagens naturais. Em seguida, era tomada a mesma abordagem para os aspectos brasileiros (ROCHA, 2000).

[...] a disciplina Geografia passa a ter um novo status no currículo escolar. Influenciado pelo modelo curricular francês, no novo estabelecimento de ensino predominavam os estudos literários, mas apesar de não serem a parte mais importante daquele currículo estavam presentes as Ciências Físicas e Naturais, a História, as Línguas Modernas e a Geografia. Durante quase todo o Período Imperial, o ensino de Geografia manteve-se quase que inalterado em suas características principais, tendo sofrido poucas alterações no que diz respeito ao conteúdo ensinado ou mesmo na forma de ensinar. Praticou-se durante todo o período, a Geografia escolar de nítida orientação classista, ou seja, a Geografia descritiva, mnemônica, enciclopédica, distante da realidade do(a) aluno(a) (ROCHA, 2000, p. 131).

Entretanto, apesar de todo o investimento e alarde que representou a instalação do Colégio Pedro II, o qual se tornou referência e parâmetro de currículo para a educação nacional, o ensino de maneira geral era uma realidade totalmente lançada ao descaso nas demais regiões do Brasil, excetuando algumas províncias de economias mais desenvolvidas em que havia alguns liceus e escolas a cargo das autoridades locais. Fica claro também que a Geografia institucionalizada no meio escolar tinha como referencial a memorização e os enunciados dos poucos materiais didáticos do período. Inexistiam professores de Geografia, os professores desta disciplina eram figurados por advogados, engenheiros, médicos, seminaristas, entre outros. Em relação à qualidade dos conteúdos e didáticas geográficas, tinham como característica a apresentação de temários particularizados e estanques, uma fragmentação teórica que não fazia sentido com a totalidade do território nacional.

Até o findar da monarquia pouca coisa mudou na estrutura educacional do país, o acesso $\frac{\text { à educação continuava centralizado nas maiores cidades e a garantia de acesso aos cursos }}{\text { Oliveira et al, } 2019 .}$ 
secundário e principalmente nas Academias estava restrita as proles da elite nacional. Em meados do século XIX, a geografia e história do Brasil ganharam patamar de ensino específico e passaram a serem lecionadas separadamente, contudo, a Geografia escolar vai percorrer praticamente todo este século se pautando na descrição, na nomenclatura dos lugares e acidentes geográficos, entre outras memorizações lineares da Geografia. A principal referência teórica do período estava ainda fundada na obra "Corografia Brazilica" de autoria do Padre Manuel Aires de Casal, a qual foi publicada pela Imprensa Régia ainda em 1817. Em relação a este escrito Prado Júnior (1955) coloca que "não se percebe nele vocação ou instinto científico algum, isto é, qualidade de observação, análise, comparação e síntese, que fazem a base do pensamento nas ciências. Nada disto ele possui; é um simples colecionador e registrador de fatos" (p. 53).

De acordo com Rocha (2000), este cenário terá algumas incursões ideológicas com o advento da República, um discurso cívico-patriótica que esteve voltado em legitimar o novo regime, sendo que a Geografia novamente é utilizada enquanto uma das ferramentas de convencimento e de formação de "brasileiros". Entretanto, até os primeiros anos do século XX a Geografia mantinha um caráter geral de disciplina pautada no ensino enciclopédico, propedêutico e acrítico. Com isso, "[...] a análise ficava limitada ao aspecto fisionômico, descrição daquilo que os levantamentos empíricos estavam mostrando" (SILVA, 1996, p. 131).Em relação ao ensino de maneira geral:

\footnotetext{
Aparentemente o século XX começava não muito diferente de seu antecessor: a República não cumprira as promessas; o Estado limitava-se a cooperar com certos autores e a resolver casos específicos, omitindo-se do problema geral e deixando de implementar uma política efetivamente eficiente. As dificuldades vão se transmitindo de geração a geração até 1930, ano de muita mudança política, que traz de volta a idéia de tratar da instrução através de uma agência especifica, o Ministério da Educação, na ocasião acoplado ao da Saúde (LAJOLO; ZILBERMAN, 2009, p. 156)
}

Será apenas na década de 1930 que a Geografia brasileira começará a construir uma identidade própria, ainda que inteiramente influenciada pelos ensinamentos dos mestres franceses, com destaque para os professores Pierre Deffontaines e Pierre Monbeig (ANDRADE, 1987). Portanto, uma Geografia própria, “[...] seja ela acadêmica, seja a escolar, institucionalizou-se no início do século XX, via Sociedade Brasileira de Geografia Estatística, Universidade de São Paulo, e outras instituições [...] essa institucionalização está vinculada ao seu ensino [...]" (CAVALCANTE, 2008, p. 21). É então com o surgimento da Universidade de São Paulo (USP) em 1934, que a geografia vai aparecer pela primeira vez enquanto curso 
superior no país. Ainda agregada ao curso de História, a Geografia obtém a sua "cidadania acadêmica em 1957 quando se separa da História (CAVALCANTE, 2008).

Conforme Andrade (1987), os livros didáticos deste período escritos Delgado de Carvalho e Aroldo de Azevedo estavam alinhados com a escola francesa de Geografia (Possibilismo Geográfico), “[...] inaugurando uma Geografia humana explícita [...] [...] uma concepção liberal, bem ao gosto da burguesia agroindustrial paulista que na conjuntura dos anos trinta teme radicalismos de qualquer matriz" (MORAES, 1988, p. 125). Portanto, se diz um embasamento nos pressupostos da Geografia Tradicional, de traços assentados no empirismo e atrelado nos acontecimentos isolados do espaço geográfico, uma herança ainda bastante viva dos postulados positivistas. Segundo o Parâmetro Curricular Nacional, (1998, p. 21):

Os alunos eram orientados a descrever, relacionar os fatos naturais e sociais, fazer analogias entre eles e elaborar suas generalizações ou sínteses. Explicá-las sim, porém evitando qualquer forma de compreensão ou subjetividade que confundisse o observador com o objeto de análise. Pretendia-se ensinar uma Geografia neutra [...].

Entretanto, após o surgimento dos cursos de Geografia, inicialmente na USP e depois sua propagação por outras universidades do país, a Geografia brasileira ganha maturidade e passa a ter significativas contribuições no cenário internacional. Como exemplo pode-se destacar o primeiro trabalho doutoral em Geografia defendido no país em 1944, uma pesquisa da professora Maria da Conceição Vicente de Carvalho, intitulado "Santos e a Geografia Urbana do Litoral Paulista”. Já em 1956, o Brasil sediou o XVIII Congresso Internacional de Geografia, no Rio de Janeiro, com a participação de geógrafos do mundo inteiro. Portanto, apesar dos desafios e dificuldade característicos da realidade brasileira, a Geografia científica brasileira se constituiu com uma identidade própria e foi aos poucos fornecendo subsídio para a Geografia escola local (MORAES, 2005).

Na segunda metade do século XX, a influência marxista irá forjar uma Geografia Crítica que passa a questionar as Geografias produzidas até então e a própria estrutura social. No caso brasileiro, os arbítrios do capital que fazia uso da "mão de ferro" dos governos militares para impor a maximização capitalista, bem como a onda neoliberal que varreu a América Latina após os anos 1980 passam a ser objeto de questionamento e reflexão da Geografia. Toda esta estrutura social exerceu influência direta na realidade social do país, incluindo a própria 
educação, uma vez que nos "anos de chumbo" a Geografia e a História foram abolidas ${ }^{1}$ em nome de um currículo de cunho nacionalista. Ou seja, a reformulação do Ensino Superior e do Ensino Médio deste período buscou reduzir o conteúdo de Humanas, pois os considerava "subversivos", e institucionalizou os chamados "Estudos Sociais" (TONINI, 2011). "O centro de preocupação da Geografia Crítica passa a ser as relações entre a sociedade, o trabalho e a natureza na produção do espaço, exigindo dessa forma, a negação dos velhos pressupostos da Geografia Tradicional" (STRAFORINI, 2004, p. 67).

Com isso, chega-se a uma Geografia questionadora e que tenha o espaço enquanto uma realidade totalitária, a qual se posicione para além da dimensão empírico-descritiva da relação homem-natureza e nem se resuma na interpretação socioeconômica e política do mundo. Portanto, uma escolarização geográfica “[...] que trabalhe tanto as relações socioculturais da paisagem como os elementos físicos e biológicos que dela fazem parte, investigando as múltiplas interações entre eles estabelecidas na constituição de um espaço: o espaço geográfico" (BRASIL, 1998, p. 20). Enfim, a Geografia tem se posicionado enquanto uma ciência do espaço e que está conduzida de forma alinhada as realidades sociais vigentes, sendo que o seu atual estágio de maturidade lhe possibilita questionar às 'imposições' e 'arbítrios' colocadas pela estrutura social. É nessa Geografia que a escolarização nacional carece, não deixando é claro, de reconhecer todo o processo de amadurecimento com que esta ciência vem passando desde a sua sistematização ainda no século XIX.

Esse complexo e desafiador caminho que permeou/permeia a construção da disciplina geográfica é uma característica que deve fundamentar a formação/atuação dos Licenciados em Geografia, reunindo nesse processo uma capacidade substancial de síntese das várias geografias que compõem essa ciência (BEZERRA; MELO, 2018). Dada essa questão, é possível afirmar que o ensino tem (ou deveria ter) a intencionalidade de ser o elo entre as várias disciplinas do meio social, consideração essa que ganha ainda mais sentido quando se trás à tona a Geografia, uma vez que essa busca constantemente a reflexão/compreensão do Espaço Geográfico.

\footnotetext{
${ }^{1}$ A eliminação da Geografia e da História do currículo concorreria para empobrecer a formação humanística da juventude, comprometendo de forma grave seu preparo integral e equivaleria ao fracasso do ensino em si mesmo, o qual visa preparar futuros cidadãos munidos de um rico pano de fundo de cultura, do qual nem a Geografia, nem a História podem estar ausentes. E a adoção dos Estudos Sociais da maneira como vem sendo preconizada corresponderia a uma verdadeira supressão dos estudos geográficos e históricos em nível de 1o grau(CONTI, 1976, p. 61).
} 


\section{CONSIDERAÇÕES FINAIS}

As discussões aqui destacadas evidenciam um pouco das intencionalidades que a ciência e o ensino de maneira estiveram submetidos ao longo da história, uma verdade que acabou em certos contextos forjando um ensino voltado para a construção e/ou perpetuação de um determinado status quo da organização social. Tendo em vista a historização da Geografia em si, esta também esteve fortemente influenciada pelas ideias e pretextos de alguns grupos sociais hegemônicos, cenário que perpetuou até por volta dos anos 1980, aonde passou-se a existir uma militância por uma Geografia mais transparente e que realmente buscava desnudar a realidade social.

No entanto, é válido frisar que alguns comportamentos da Geografia Tradicional ainda se fazem presentes na contemporaneidade, situação esta que se faz mais presente na Geografia escolar, uma vez que vários professores ainda reproduzem uma escolarização pautada na descrição superficial e a memorização de dados/fatos geográficos. Portanto, neste ensaio ficou claro o prejuízo que o ensino geográfico instituído de forma alienada resulta na formação cidadã dos sujeitos, pois nesta conjuntura, a verdade social lhe é escondida em proveito de se perpetuar a continuidade de sua própria submissão, isto é, o não questionamento das decisões e instituída pela elite dominante.

Portanto, faz-se de vital importância destacar o papel e objetivo da Geografia que é o estudo e questionamento do espaço geográfico, espaço este que não é dado de forma pronta e acaba aos sujeitos, pois este é uma construção humana. Sendo um produto da ação humana, o espaço carece então de ser democraticamente entendido, participado e questionado por todos os sujeitos desta espécie animal, cabendo a Geografia de maneira geral, contribuir neste processo de emancipação humana, uma tarefa que esteja pautada na liberdade e na participação social como elemento constituinte da natureza. Enfim, “[...] o espaço deve ser considerado como uma totalidade, a exemplo da própria sociedade que lhe dá vida [...]” (SANTOS, 1978, p. 122), é a luta "Por uma Geografia Nova" (SANTOS, 1978).

Está assim colocado o desafio docente neste século XXI, compreender uma Geografia singular que desconsidere suas inúmeras subdivisões: agrária e urbana; ensino e científica; física e humana; entre outras dicotomias conteudistas. Esta verdade está em Santos (1994, p. 50) ao colocar que “[...] não há geografia física que não seja uma parte da geografia humana. $\mathrm{O}$ que há, na verdade é uma geografia do homem [...]”. É inicialmente pelo próprio Geógrafo 
(Bacharel e Licenciado) que esta ciência carece de ser singularizada enquanto um esforço de entender e explicar sinergicamente o espaço, sendo que os professores de Geografia na educação básica acabam exercendo uma importância capital na superação desta problemática ainda presente no meio escolar contemporâneo.

\section{REFERÊNCIAS}

ANDRADE, M. C. Geografia, ciência da sociedade: uma introdução à análise do pensamento geográfico. São Paulo: Atlas, 1987.

BAUAB, F. P. Da Geografia Medieval às origens da Geografia Moderna: contrastes entre diferentes noções de Natureza, Espaço e Tempo. 2005. Tese (Doutorado em Geografia) Programa de Pós Graduação em Geografia, UNESP, Presidente Prudente - SP.

BEZERRA, J. B.; MELO, F. P. Os dilemas da Tríade Geografia Física, Humana e Disciplinas Pedagógicas na Formação do Licenciado em Geografia. I Colóquio Internacional de Educação Geográfica. Universidade Federal de Alagoas - Maceió/AL, 2018. Disponível em: http://www.seer.ufal.br/index.php/educacaogeografica/article/view/4429. Acesso em: 16 nov. 2019.

BRASIL. Parâmetros Curriculares Nacionais. Ministério da Educação e do Desporto. Secretaria da Educação Fundamental. Brasília: MEC/SEF, 1998.

CALLAI, H. C. A Geografia e a Escola: Muda a Geografia? Muda o Ensino? Revista Terra Livre, n. 16. (p. 133-152). São Paulo, 2001.

Grupo, espaço e tempo nas séries iniciais. In: CASTROGIOVANI, A. C. et al. (Orgs.). Geografia em sala de aula: práticas e reflexões. Porto Alegre: Associação dos Geógrafos Brasileiros, 1998.

CAVALCANTI, L. S. Ensino de Geografia e Diversidade: construção de conhecimentos geográficos escolares e atribuição de significados pelos diversos sujeitos do processo de ensino. São Paulo: Contexto, 2006.

A geografia escolar e a cidade: Ensaios sobre o ensino de geografia para a vida urbana cotidiana. Campinas, SP: Papirus, 2008.

CHAUÍ, M. Seminários: o nacional e o popular na cultura brasileira. São Paulo: Brasiliense, 1983.

CORRÊA, R. L. Região e organização espacial. 4a . ed. São Paulo: Ática, 1991.

CONTI, J. B. A reforma do ensino de 1971 e a situação da Geografia. Boletim Paulista de Geografia. Associação dos Geógrafos Brasileiros - Seção São Paulo, nº 51, 1976. 
FELICIANO, L. A. S. O Ensino de Geografia no Brasil: Do Colégio Pedro II á Universidade de São Paulo (1837 á 1934). XIII EDUCERE, IV SIRSSE, VI SIPDCATEDRA UNESCO, (Congresso), 2015. Disponível em: http://educere.bruc.com.br/arquivo /pdf2017/25271_12024.pdf. Acesso em: 25 abr. 2019.

FERREIRA, C. C.; SIMÕES, N. N. A evolução do pensamento geográfico. Lisboa: Gradiva, 1990.

GUIMARÃES, M. L. S. Historiografia e nação no Brasil: 1838-1857. Rio de Janeiro: EdUERJ, 2011.

LACOSTE, Y. A geografia, isso serve, em primeiro lugar, para fazer a guerra. Tradução Maria Cecília França. Campinas: Papirus, 1993.

LAJOLO, M.; ZILBERMAN, R. A formação da leitura no Brasil. 3 ed. São Paulo: Editora Ática, 2009.

LANDIM NETO, F. O.; BARBOSA, M. E. S. O ensino de geografia na educação básica: uma análise da relação entre a formação do docente e sua atuação na Geografia escolar. Revista eletrônica Geosaberes. v. 1, n. 2, dez/2010.

LAKATOS, E. M. Fundamentos de metodologia científica. 3. ed, São Paulo: Atlas, 1991.

LENCIONI, S. Região e geografia. São Paulo: Editora da Universidade de São Paulo, 1999.

MARCONI, M. A.; LAKATOS, E. M. Fundamentos de metodologia científica. 5. ed. Atlas, São Paulo, 2003.

MELO, F. P. (Re) Pensando o Ensino de Geografia e seus Mitos. Revista Saberes, Paripiranga, Bahia, Brasil, v. 1, n. 6, p. 2-10, mai./ago. 2018. Disponível em: http://npu.faculd adeages.com.br/index.php/revistasaberes/article/view/81/57. Acesso em: 26 nov. 2019.

MORAES, A. C. R. Geografia: Pequena História Crítica. 20. ed., São Paulo: Annablume, 2005.

1988.

. Ideologias geográficas: espaço, cultura e política no Brasil. São Paulo: HUCITEC,

PRADO JÚNIOR, C. A evolução da Geografia e a posição de Aires de Casal. Boletim Paulista de Geografia, 19: 52-66, 1955.

PONTUSCHKA, N. N.; PAGANELLI, I.T; CACETE, H. N. A Interdisciplinaridade e o ensino de Geografia. In . Para ensinar e aprender Geografia. 3.ed. São Paulo: Cortez, 2009.

PEREIRA, R. M. F. A. Da Geografia que se ensina à gênese da Geografia moderna. 3. ed. Florianópolis: ed. UFSC, 1999.

RIBAS, A. D. A Antiguidade Clássica: Filosofia, Ciência e Geografia, 2015 (mimeo.). 
ROCHA, G. O. R. Uma breve história da formação do(a) professor(a) de Geografia no Brasil. Terra Livre, São Paulo, nº 15, p.129-144, 2000.

SANTOS, M. Por uma Geografia Nova. São Paulo: Hucitec, Edusp, 1978.

Metamorfose do Espaço Habitado. 3.ed. São Paulo: Hucitec, 1994.

SILVA, J. L. B. Notas introdutórias de um itinerário interpretativo sobre a formação do pensamento geográfico brasileiro. $219 \mathrm{f}$. Dissertação (Mestrado em Geografia). Faculdade de Filosofia, Letras e Ciências Humanas, Universidade de São Paulo, São Paulo, 1996.

TONINI, M. I. (Org.). O ensino de Geografia e suas Concepções Curriculares. Porto Alegre: Ufrgs, 2011.

. Geografia escolar: uma história sobre seus discursos pedagógicos. 2. Ed. Ijuí: Ed. Unijuí, 2006.

STRAFORORINI, R. Ensinar geografia: o desafio da totalidade-mundo nas séries iniciais. São Paulo: Annablume, 2004.

VLACH, V. R. F. Ideologia do nacionalismo patriótico. In: Para onde vai o ensino de Geografia. Ariovaldo Umbelino de Oliveira (Org.). São Paulo: Contexto, 1994.

. Ensino de geografia e história do pensamento geográfico brasileiro: notas a respeito do papel do território no Brasil (1822 - 1934) In. Bonfim, P. Org; Souza Neto, M. (Org) Geografia e Pensamento geográfico no Brasil. São Paulo: Annablume; FFLCHUSP: GEOPO-USP, 2010. 